LIAMES 4 - pp. 83-89, Primavera 2004

Wilmar da Rocha D'Angelis (IEL-UNICAMP)

Daniela Sampaio Bonafé Fernandes

(Graduação em Lingüistica-UNICAMP)

\title{
O vocabulário Kaingáng de Ambrosetti (1894) e as relações lingüísticas e históricas da Aldeia de Ingacorá (RS) com Misiones (Arg.)
}

\section{RESUMO}

Em 1892 e 1894 o pesquisador argentino Juan Bautista Ambrosetti visitou e realizou pesquisa junto à então única comunidade Kaingang vivendo fora do Brasil, nas proximidades de San Pedro (Misiones). Entre os resultados que publicou inclui-se um valioso vocabulário, seja por seu ineditismo, seja por ser um dos únicos documentos desse tipo conhecidos sobre os Kaingang de Misiones, seja, ainda, por sua extensão. No Brasil o trabalho de Ambrosetti só começou a ser conhecido e efetivamente citado quase 100 anos depois de sua publicação, mas continua sendo documento de difícil acesso. Esse texto traz informação do trabalho em andamento para dar ao vocabulário de Ambrosetti uma divulgação ampla e, ao mesmo tempo, de como esse vocabulário foi empregado em pesquisa (com apoio da FAPESP), para identificar relações históricas, através da filiação lingüística, entre a comunidade Kaingang de Inhacorá (RS) e as comunidades Kaingang que existiram na Argentina.

PALAVRAS-CHAVE Kaingáng; dialetos; Misiones (Argentina); Ambrosetti.

\section{RESUMEN}

En los años 1892 y 1894, el investigador argentino Juan Bautista Ambrosetti visitó y realizó investigaciones en la única comunidad indígena Kaingang afuera de los límites del territorio brasileño, en la proximidad de San Pedro (Misiones). Entre los resultados que publicó se incluye un valioso vocabulario, sea por su condición pionera, sea por ser uno de los únicos documentos de ese tipo acerca de los Kaingang de Misiones, y más aún por su extensión. En Brasil el trabajo de Ambrosetti solamente empezó a ser conocido y efectivamente citado casi 100 años después de su publicación, pero sigue siendo un documento de difícil acceso. Ese texto trae información del trabajo realizado para dar al vocabulario de Ambrosetti una divulgación amplia y, también, de cómo ese vocabulario fue empleado en una investigación (con el apoyo de la FAPESP) con objetivo de, por medio de la filiación lingüística, identificar relaciones históricas entre la comunidad Kaingang de Inhacorá (RS) y las comunidades Kaingang que existieron en Argentina.

Palabras llave Kaingáng; dialectos; Misiones (Argentina); Ambrosetti. 


\section{UMPOUCODEHISTÓRIA}

Sabia-se, no século XIX, da existência de comunidades Kaingáng no território hoje argentino de Misiones. Aquela região integrava, então, a vasta zona litigiosa entre Brasil e Argentina, no que ficou conhecida como a "Questão das Missões", conflito só encerrado na última década do século XIX pela arbitragem do Presidente dos Estados Unidos. Também se pode contar como região de litígio entre Argentina e Paraguai, porque parte dela só passou a efetivo domínio argentino depois da derrota de Solano Lopez. Como zona litigiosa, era muitas vezes mencionada, na documentação oficial, como território paranaense (uma vez que até a segunda década do século XX a região oeste catarinense pertencia ao Paraná). Por esse motivo, também, muitas vezes referências aos Kaingáng de Misiones passaram desapercebidas aos pesquisadores, uma vez que na documentação oficial do Rio Grande do Sul, por exemplo, algumas vezes são mencionados como "índios do Paraná".

A região de San Pedro, centro do território de Misiones, constitui uma continuidade natural do ecossistema típico da ocupação Kaingáng, como é o do oeste catarinense atual. Efetivamente aqueles grupos Kaingáng mantiveram a soberania de seu território, nos pinheirais e ervais de Misiones, até pelo menos a década de 1870, quando grupos econômicos argentinos patrocinaram a entrada para a região dos ervais missioneiros, em função da quebra do sistema produtivo paraguaio (que abastecia o mercado argentino), na famosa Guerra do Paraguai.

Na década de 1890 um pesquisador argentino, Juan Bautista Ambrosetti, fez três viagens a Misiones, incluindo nelas uma pesquisa com o grupo Kaingáng então remanescente em San Pedro. Em 1894 Ambrosetti publicou seu mais completo trabalho sobre o grupo e que incluía, além de uma boa memória histórica e um esboço etnográfico, um extenso vocabulário, um dos únicos e o mais importante vocabulário Kaingáng colhido em Misiones.

Ambrosetti encontrou, como cacique dos Kaingáng de San Pedro, Bonifácio Maidana, um argentino criado pelos índios. Maidana fora capturado na década de 1840, quando os Kaingáng, liderados pelo seu então cacique, Facrán, atacaram e dizimaram uma turma de ervateiros que tentava penetrar em seu território. Facrán, conforme sabemos por outras fontes, teria crescido em Guarapuava, onde fora catecúmeno do Pe. Francisco Chagas Lima, tendo depois abandonado aquela aldeia e se internado com seu grupo para a região de Misiones ${ }^{1}$.

Segundo registrou Ambrosetti, na idade adulta Bonifácio Maidana se tornara líder de um grupo e na década de 1860, por divergirem sobre o modo de relacionar-se com os brancos (aceitando ou não relações amistosas), os dois grupos entraram em confronto, e o grupo de Facrán teria atravessado o Rio Uruguai, passando ao Rio Grande do Sul.

\footnotetext{
${ }^{1}$ Sabemos que isso não era um fato tão incomum. Vitorino Condá, famoso cacique Kaingáng da região de Palmas e Xapecó nos meados do século XIX, também crescera em Guarapuava, junto à Real Expedição que ali se estabeleceu na década de 1810. Quanto ao nome do antigo cacique de Misiones, também se encontram documentos com o registro "Fracrán".
} 
Pesquisando a história de Misiones, em paralelo com a documentação de fontes primárias da história indígena do Sul do Brasil, D’Angelis $(1994,1997)$ concluiu que um grupo vindo de Misiones foi atacado pelo grupo do cacique Fongue, de Guarita (RS), com o qual veio, depois, a estabelecer aliança, indo se estabelecer e formar o que é hoje a comunidade Kaingáng de Inhacorá (atualmente, município de São Valério do Sul, RS) ${ }^{2}$.

Na memória oral dos Kaingáng de Inhacorá, o grupo com que Fongue fez aliança era liderado por um tal cacique Silva. Como aliados, mas não como grupo único, a gente de Fongue e a gente do cacique Silva se estabeleceram na banda leste ${ }^{3}$ do curso médio do Rio Inhacorá, dividindo os respectivos toldos ${ }^{4}$ pelo Lajeado do Tigre, afluente do Inhacorá. O grupo do cacique Fongue ficou ao norte do Lajeado do Tigre, constituindo a aldeia denominada $\mathrm{Gu}^{5}$, ou seja, "de baixo". O grupo do Silva ficou ao sul do Lajeado Tigre, onde hoje se encontra a aldeia sede do Posto Inhacorá.

Desde então os grupos viveram assim, próximos como aliados, mas administrando as tensões que, vez ou outra, cresciam. Como aliados, participavam juntos de expedições guerreiras contra outros grupos, e tudo indica que outros episódios envolvendo alianças trouxeram para a comunidade pessoas de outros grupos, incluindo, pelo que indicam os relatos dos mais velhos, grupos Xokléng.

Entretanto, no começo da década de 1960 o governo do Rio Grande do Sul, que administrava a maior parte das áreas indígenas no Estado, realizou um processo de esbulho generalizado contra as terras indígenas, chegando mesmo a suprimir completamente certas áreas, como Ventarra e Serrinha. No Inhacorá as terras ao norte do Lajeado Tigre foram tomadas pelo Estado, e os dois grupos descendentes de Fongue e de Silva foram reunidos numa única aldeia, não sem conflitos e consequiências. Das terras tomadas da comunidade indígena, uma parte ficou com o próprio Estado do Rio Grande do Sul, que ali estabeleceu uma Estação Experimental de agricultura, enquanto a outra parte foi loteada e entregue a pequenos agricultores, constituindo-se algumas comunidades não-índias sobre a terra dos índios, sendo a principal delas o distrito de Coroados.

\section{O VOCABULÁRIO DE AMBROSETTI}

Como se disse, o vocabulário de Ambrosetti parece ser o mais importante e extenso da língua Kaingáng tomado em Misiones, mas poucas vezes foi tomado em consideração por pesquisadores no Brasil. É difícil, à primeira vista, decidir se Ambrosetti faz boa ou má transcrição. A dúvida vem do fato de se observar facilmente alguns termos cuja anotação por Ambrosetti contrariam todos os registros conhecidos, causando a impressão de tratar-se de imperícia ou "falta de ouvido", mas por outro lado, encontram-se cuidados quase preciosos no registro de certas qualidades vocálicas, com o emprego de diacríticos para

\footnotetext{
${ }^{2}$ Na atual ortografia Kaingáng, o nome do cacique é grafado Fãg. A pronúncia é [fõn].

${ }^{3}$ Optamos pelo termo "banda", para evitar o termo "margem", que se prestaria a equívocos, uma vez que as aldeias Kaingáng nunca são diretamente na margem dos rios.

${ }^{4}$ Toldo é termo regional, no Sul, de origem castelhana, significando "aldeia indígena".

5 [' $\overline{\text { ggu }] . ~}$
} 
distinguir longas e breves. Do primeiro tipo há registros como Gŏnge, para Carayá (bugio ou guariba), onde o registro do "e" final parece aproximar Ambrosetti dos anotadores

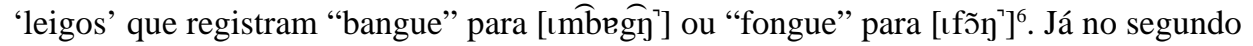
caso, pode-se ver como o detalhe fonético é capturado em uma anotação como a que faz para o termo pálpebra = Kané fŭerĕ , quando sabemos que o "u" é labialização oriunda da consoante labial e o último "e" é apoio vocálico da soltura do "r" (uma transcrição um pouco menos detalhista apanharia algo como [ıfərə] ).

Outro fato que depõe contra a qualidade da anotação do pesquisador argentino no final do século XIX é o uso de duas letras diferentes para representar o mesmo som, como é o caso da fricativa glotal [h], para a qual ora utiliza $h$, como em Ñë̈r-kunguhú, ora utiliza j, como em Pejú ${ }^{7}$.

Causa também alguma dificuldade o fato de que em algumas palavras do vocabulário apareça um som típico do Guarani (mas não do Kaingáng), a saber, a africada alveo-palatal [d3]. Por exemplo, em: Oso hormiguero - Djatý, quando a forma que se ouve, entre os Kaingáng do Rio Grande do Sul e Santa Catarina, para uma das variedades de tamanduá é [jołti]. O aparecimento de $d j$ se explicaria pelo fato de que um de seus informantes provavelmente tenha sido Bonifácio Maidana, um menino argentino, falante nativo de Guarani, que veio a ser 'adotado' pelos Kaingáng aos 10 anos de idade (em 1840), e que Ambrosetti encontrou já como Cacique do grupo, nos anos de 1892 e 1894, quando Maidana contava pouco mais de 60 anos. O mesmo vale para anta, que em Ambrosetti aparece como Odjŭ́r, quando nos dialetos Kaingáng do RS e SC ouve-se [॰-jor]. Em algumas palavras pode-se mesmo reconhecer claramente o Guarani, como o registro de Ambrosetti para o nome do peixe Dourado, que aparece como Pirá-djú, quando para os Kaingáng o termo (emprestado certamente do Guarani) é [pirว̃-ju].

Por não ser treinado em pesquisa fonética, Ambrosetti faz algumas aproximações,

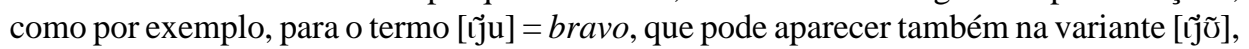

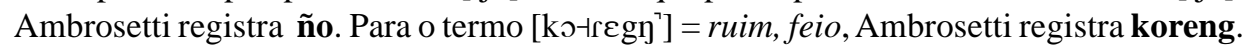

Em outros casos há omissões como, por exemplo, da oclusiva glotal: veja-se por exemplo, em Ambrosetti, arara = Keén, que em dialetos brasileiros atuais pode-se

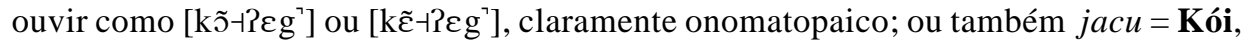
que em dialetos brasileiros atuais pronuncia-se [kっ-?i].

Apesar dessas aparentes falhas de transcrição o vocabulário colhido por Ambrosetti em Misiones é de extrema importância. Além de ser quase único registro do dialeto falado em Misiones, é um vocabulário muito extenso, quase inusual para a época: em suas 30 páginas há mais de 850 ítens lexicais (sendo 242 verbos) e mais de 70 frases, incluindo expressões idiomáticas (veja-se: “sensual como gallo”). Compare-se, por exemplo, com o

\footnotetext{
${ }^{6}$ Por exemplo, no vocabulário que colheu com duas "mulheres dos Coroados", de Guarapuava, que encontrou em sua viagem ao Paraná, Auguste de Saint-Hilaire registrou Aranguerê para [røgygre] = irmão (cf. Saint-Hilaire [1851] 1978:82).

${ }^{7}$ Restaria a hipótese de tratar-se, mesmo, de realizações de sons distintos, mas essa hipótese fica enfraquecida por duas circunstâncias: (i) em dialetos do Kaingáng no Brasil as duas palavras usadas como exemplo apresentam, nos lugares de $h$ e de $j$, um mesmo fone fricativo surdo; (ii) em muitos dialetos do espanhol a letra $j$ tem o valor sonoro de $[\mathrm{h}]$.
} 
vocabulário publicado por Telêmaco Borba no início do século XX, dos Kaingáng do norte paranaense, que apresenta cerca de 700 ítens lexicais (incluindo cerca de 70 verbos) distribuídos em 20 páginas ${ }^{8}$.

Talvez um dos mais importantes usos possíveis desse vocabulário de Ambrosetti seja para comparação dialetal e, com isso, possa contribuir à compreensão da história da dispersão, das lutas e alianças dos diferentes grupos Kaingáng. Tudo isso, aliás, levou a um desdobramento do projeto, investindo-se na transposição desse vocabulário para um arquivo informatizado com vistas à sua publicação, de modo a torná-lo mais acessível a pesquisadores brasileiros (lingüistas, antropólogos e historiadores).

\section{DA HISTÓRIA À LÍNGUA}

Em 1996 a escola da comunidade Kaingáng de Inhacorá passou a contar com novos professores indígenas, formados pela Unijuí. No entanto, esses professores encontravamse desorientados quanto à forma de alfabetizar, e sobretudo, quanto a como decidir a língua de alfabetização, questão crucial em que sua formação deixara a desejar. No ano de 1997 fizeram a experiência de tentar alfabetizar duas turmas em Português e uma turma em Kaingáng. Depois disso, buscaram assessoria lingüística para avaliar os resultados. Desde então a Escola Indígena Marechal Rondon, da aldeia Inhacorá, conta com assessoria permanente de um lingüista e uma antropóloga para avaliação e planejamento semestral, e formação continuada dos professores .

Nesse contexto de planejamento escolar é que surgiram questões interessantes de ordem lingüística e que levaram os assessores a indagar-se - conhecendo as origens da aldeia - se, afinal, não haveria permanência de diferenças dialetais naquela comunidade indígena. Considerando o entendimento comum dos professores indígenas daquela área, segundo o qual a língua Kaingáng a ser ensinada na escola deve ser aquela falada na comunidade (ou seja, o dialeto local), os assessores mostraram aos professores a importância de se conhecer qual é, realmente, o dialeto falado na comunidade ${ }^{10}$.

Em 2001 criou-se uma proposta de realizar uma investigação auxiliar ao programa de educação escolar, voltada exatamente a descobrir como é ou quais são os falares Kaingáng no Inhacorá. A estudante de Lingüística que também subscreve esse texto integrou-se a essa pesquisa, iniciando sua preparação por uma aproximação à história e cultura Kaingáng, seguida de uma aproximação à língua Kaingáng e treino em transcrição fonética ${ }^{11}$.

\footnotetext{
${ }^{8}$ Cf. Borba 1908:95-114.

${ }^{9} \mathrm{O}$ acompanhamento é feito pela antropóloga Juracilda Veiga e pelo lingüista Wilmar D’Angelis.

${ }^{10}$ É importante lembrar que, dúvidas sobre a pronúncia 'correta' de determinadas palavras surgiram com certa freqüência, entre os professores indígenas, durante os últimos quatro anos e meio em que vêm sendo acompanhados por lingüista. Elas revelavam diferentes falares "familiares" e, em alguns casos, também as dúvidas de professores que, tendo nascido em Inhacorá, foram criados na área indígena de Guarita, ou cujos pais vieram de Guarita para morar em Inhacorá.

${ }^{11}$ Um projeto de Iniciação Científica foi apresentado à FAPESP e aprovado em dezembro de 2001 (Processo 01/10565-8).
} 
Finalmente, em abril de 2002 realizamos um primeiro levantamento exploratório, em campo, através de entrevistas com pessoas de ambos os sexos e representativas de três grandes faixas etárias: jovens (até 30 anos), adultos (entre 30 e 60 anos) e idosos (acima de 60 anos $)^{12}$.

Nessa viagem a campo foram entrevistados 24 falantes - sendo 14 homens e 10 mulheres - com idades entre 15 e 90 anos. A primeira parte da entrevista consistia em informações pessoais, cujo objetivo era identificar diferentes origens e suas possíveis relações com particularidades dialetais. Foi pedido a cada falante entrevistado os nomes e local de origem dos pais e, quando o entrevistado sabia, também de seus avós. Cedo percebemos que poderia ser muito relevante saber se o sujeito ou sua família eram naturais daquela aldeia mesmo ou vinham do "Gu", a aldeia cujas terras foram usurpadas nos anos 60. Ainda que isso não venha a revelar ou refletir-se em diferenças dialetais, representa elemento importante da identidade local.

Depois das perguntas mencionadas, passava-se a um questionário de aproximadamente 55 palavras ou locuções nominais que eram apresentadas em Português e, para as quais se pedia ao falante os termos correspondentes em Kaingáng ${ }^{13}$.

O conjunto de 55 palavras foi constituído como um recorte dentro do recorte feito no Vocabulário de Ambrosetti (1894), do qual haviam sido selecionados 179 ítens. A seleção buscou incluir: (i) termos que já se sabe possuírem, no Kaingáng, mais de um correlato, dependendo da região de origem (por exemplo: há aldeias Kaingáng que possuem um termo próprio para "canoa", enquanto outras desconhecem; há aldeias Kaingáng que possuem um termo próprio para "cachorro", enquanto outras usam empréstimo ao Português); (ii) termos para os quais se prevê o uso de empréstimos ou neologismos, o que pode gerar tanto empréstimos bastante distintos entre si ou empréstimos se opondo a neologismos, como pode gerar empréstimos semelhantes mas com ajustes fonológicos que revelam diferenças dialetais no componente dos sons (por exemplo: "arma de fogo" ou "padre"); (iii) termos para os quais se sabe que a palavra Kaingáng correspondente contém uma

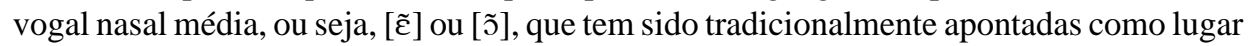
de diferenciação dialetal (cf. Wiesemann 1967:2).

A pesquisa de campo foi bem recebida pela comunidade, que cooperou com o trabalho de coleta de dados. As sessões de pesquisa foram gravadas (exceto quando o falante manifestou contrariedade) e a transcrição fonética foi feita ao mesmo tempo, na própria sessão de trabalho com o falante.

Houve algumas interessantes surpresas, como encontrar o termo [mbo-kñ], alternando com [mbołkz̃], para arma de fogo, como também o registrara Ambrosetti (1894:365), que o atribuiu a empréstimo do Guarani “mbocá”. Também ouvimos termos que parecem, ao próprio grupo, raridades, como a informação de que os antigos podiam chamar à galinha, [pedniju-mi].

\footnotetext{
${ }^{12}$ A viagem de pesquisa contou com apoio de recursos do FAEP-Unicamp.

${ }^{13}$ Para alguns falantes foi apresentado um 'mostruário' de cores (um conjunto de canetas coloridas), pedindo-se que dessem os nomes delas.
} 
Por fim, pelos dados preliminares - ainda em análise -, parece provável que se confirme haver, na área em questão, ao menos dois padrões de pronúncia, relacionados à origem dos falantes (e no caso dos mais jovens, à origem dos pais e avós) em uma ou outra das aldeias que formavam o Inhacorá até o final da década de 1950.

\section{CONCLUINDO}

A partir das entrevistas exploratórias realizadas em abril, foram selecionados alguns falantes para serem entrevistados com um questionário mais extenso e abrangente, numa segunda viagem a campo ${ }^{14}$. Esse questionário extenso deve calcar-se ainda em Ambrosetti, uma vez que avaliamos que a escolha feita, de tomar aquele autor como referência, mostrou-se bastante útil e encontra eco na cultura da comunidade.

Por fim, vale registrar que a ocorrência de certos registros nos surpreenderiam se não tivéssemos nós mesmos tomado diretamente com os falantes, como a forma [mbag'], com

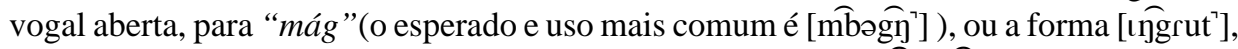
para "grun", terminada em consoante surda (o mais comum é [ı̄ggrudn'] ). Esses registros podem vir a colocar sob suspeita os questionamentos às transcrições de Ambrosetti.

\section{REFERÊNCIAS BIBLIOGRÁFICAS}

AMBROSETTI, Juan B. (1894). Los índios Kaingángues de San Pedro (Misiones). Revista del Jardin Zoológico de Buenos Aires. Buenos Aires, v.2, n.10-12, p.305-387.

BORBA, Telêmaco A.M. (1908). Actualidade indígena. Curitiba: Impressora Paranaense.

D’ANGELIS, Wilmar da Rocha. (1994). Os Kaingáng ("Tupi”) de Misiones: como montar um quebra-cabeças histórico. In XII ENCONTRO REGIONAL DE HISTÓRIA. Campinas, Unicamp, ANPUH - Assoc. Nacional de História, 5 a 7 setembro 1994

.(1997). História dos Kaingáng de Misiones (Argentina) e suas relações com o Brasil. In V ENCONTRO DE CIENTISTAS SOCIAIS. Chapecó (SC), Universidade do Oeste de Santa Catarina (UNOESC), 20 a 23 maio 1997.

SAINT-HILAIRE, Auguste de (1978). Viagem a Curitiba e Santa Catarina. Trad. Regina R. Junqueira. Belo Horizonte / São Paulo: Itatiaia / Edusp. $1^{\mathrm{a}}$ ed. francesa: 1851.

WIESEMANN, Ursula (1967). Introdução na língua Kaingáng. Rio de Janeiro: Summer Institute of Linguistics, mimeo.

${ }^{14}$ A própria ‘amostragem' será ampliada, uma vez que muitas famílias estavam fora da área indígena no tempo em que estivemos em campo. 